\title{
La reforma liberal y la construcción de la figura de Francisco Morazán como imaginario de la nación
}

\author{
Jorge Alberto Amaya \\ Docente de Historia de la UNAH
}

\section{Introducción}

Fue durante el proceso de la Reforma Liberal (1876-1900), iniciada por Marco Aurelio Soto y su primo Ramón Rosa, que se reforzaron los cimientos de la construcción del Estado-nación en Honduras. El objetivo fundamental de dichas Reformas Liberales era la modernización de las estructuras económicas y sociales con vistas a facilitar el desarrollo de las economías de exportación, atrayendo los capitales extranjeros y asegurando una cierta estabilidad política e institucional. Pero también, los reformistas calculaban que con las transformaciones introducidas, se podría por fin consolidar el Estadonación hondureño.

Este modesto artículo intentará exponer cuáles fueron algunos de los alcances de dicha Reforma en la construcción de ciertos imaginarios de nación, y en especial, intentará describir cómo los reformadores se dieron a la tarea construir un nacionalismo basado en la creación del "Panteón de los Héroes Nacionales", exaltando preferentemente a Francisco Morazán ${ }^{1}$ como el principal prócer reinante de ese

\footnotetext{
${ }^{1}$ José Francisco Morazán Quesada nació en Tegucigalpa en 1792 y murió fusilado en San José de Costa Rica en 1842. Fue un genial militar en el campo de batalla, lo que le llevó a ocupar la presidencia de la República Federal de Centroamérica entre 1830 y 1838 . Antes, había sido Jefe de Estado de Honduras en 1827. Instruido en la ideología liberal por su pariente Dionisio de Herrera, impulsó como presidente federal una serie de reformas conducentes a instaurar un Estado liberal según el modelo aplicado por los revolucionarios franceses y especialmente por los estadounidenses. Una vez disuelta la República Federal, salió rumbo a Panamá y Perú; volvió a Centroamérica en 1842 , asentándose en Costa Rica, donde fue electo Jefe de Estado tras la renuncia de Braulio Carrillo, sin embargo, una rebelión desestabilizó su régimen. Capturado tras una traición de algunos allegados, fue fusilado sin previo juicioirónicamente- el 15 de septiembre de 1842. Fue autor de Apuntes para la Revolución del 29, más conocido como Memorias (1840), así como de manifiestos, proclamas, comunicaciones, arengas y decretos que revelan al estadista y al escritor ilustrado. Con los años, se convirtió en la máxima figura histórica de Centroamérica, específicamente a partir de las Reformas Liberales que celebraron su gesta unionista y desarrollaron una "estatuaria" alrededor de su personalidad. La máxima condecoración que otorga el Estado de Honduras, fue creada el 1 de marzo de 1941 en el gobierno de
} 
"Panteón sagrado".

De este modo, analizaremos en parte la formación de la nación en Honduras y la invención de tradiciones a partir de la sacralización de la figura del General Francisco Morazán. En particular, nos interesa conocer cómo se construyó en el imaginario colectivo una tradición histórica común, cómo se "inventó" un imaginario nacional y cómo se creó y "sacralizó" el panteón de los héroes nacionales a partir de la figura de Morazán.

Conceptualmente, en este caso recurrimos al término "invención de tradiciones" en la acepción que le otorgaron Eric Hobsbawm y Terence Ranger, para quienes la "invención de tradiciones" supone tres tipos básicos de procesos: los que simbolizan cohesión social o pertenencia a grupos reales o artificiales; los que legitiman instituciones o relaciones de autoridad y los que priorizan la socialización, la enseñanza de creencias y sistemas de valores ${ }^{2}$.

En el caso de Honduras, con la "invención de la tradición" del culto al "Panteón de los héroes" y la exaltación de la figura de Morazán, basada en su gesta heroica de la República Federal y sus victorias en las batallas contra los conservadores, se difundieron por tanto nuevos sistemas de valores, derechos y obligaciones entre los hondureños del siglo XIX, como fueron el patriotismo y la lealtad a la nación. Además, Morazán y otros imaginarios nacionales fueron usados por las élites liberales de la época para construir una tradición que permitiera dar un sentido de unidad nacional y nacionalismo.

\section{1) Principales medidas en la construcción del Estado-nación durante la Reforma}

En materia política, el gobierno de Soto en principio aseguró un periodo de estabilidad política, que perduró por lo menos hasta comienzos del siglo XX. Para ello se valió fundamentalmente de la organización -por primera vez en la historia del país-, de un ejército relativamente profesional. La anarquía que había reinado en Honduras entre la disolución de la Federación y el advenimiento de la Reforma

\footnotetext{
Tiburcio Carías en homenaje al General Morazán, denominada “Orden de la Gran Cruz de Oro Francisco Morazán”. Cfr. "Honduras:Order of Francisco Morazán", En: www.medals_org-uk-honduras-images-honduras001_jpg.htm, 2001, p. 1.

${ }^{2}$ Véase: Cfr. Hobsbawm, Eric y Ranger, Terence, The Invention of Tradition, Cambridge, University Press, 1983, p. 29.
} 
La reforma liberal y la construcción de la figura de

Francisco Morazán como imaginario de la nación

fue percibida por los liberales como una de las principales causas del atraso material de la nación, por ello, se organizó un ejército profesional al servicio del Estado. Se estableció el servicio militar obligatorio en 1878 y ya para 1879 se calculaba en cerca de 20,000 milicianos. Gran parte del éxito en la constitución de un ejército nacional se debió a la contratación de los generales y héroes cubanos Máximo Gómez y Antonio $\mathrm{Maceo}^{3}$.

En el plano institucional y jurídico, un paso fundamental en la reforma fue la aprobación de la Constitución de 1880, de claro signo liberal, así como la renovación de toda la antigua legislación que fue planteada como una tarea prioritaria. La legislación vigente en el país para ese tiempo, en su mayor parte estaba compuesta por anticuadas leyes españolas provenientes de la Colonia, las cuales eran incompatibles con las reformas sugeridas por Soto y Rosa. De esa forma, el Gobierno de Soto dictó los códigos Civil, Penal, de Comercio, de Minería, de Procedimientos, de Aduanas y una ley de Tribunales, todos de inspiración liberal. Con la reestructuración efectiva de las leyes obsoletas existentes para ese entonces, los reformadores liberales crearon el marco jurídico tendente a modernizar la arcaica estructura estatal de Honduras ${ }^{4}$.

Con respecto a la "imaginación de la nación", el principal ideólogo del régimen, Ramón Rosa, estaba convencido que cada uno de los Estados centroamericanos constituían cada cual una nación, pero él era partidario de restituir a mediano o largo plazo a la "República Federal de Centroamérica". Entre tanto, se tenían que institucionalizar una serie de símbolos y representaciones de la nación que fueran internalizadas por el pueblo de manera colectiva para que coadyuvaran a fortalecer la identidad nacional.

Una de las primeras tareas de los reformistas fue la de encomendar la redacción de un libro de texto de "Historia de Honduras", pues el país carecía de una "historia nacional", con lo cual, era difícil que el pueblo se sintiera identificado con "su pasado". De este modo, el presbítero Ramón Antonio Vallejo, a petición del gobierno de Soto,

${ }^{3}$ Posas, Mario y Del Cid, Rafael, La construcción del sector público y del Estado nacional en Honduras, San José de Costa Rica, Editorial Universitaria Centroamericana (EDUCA), p. 27.

${ }^{4} \mathrm{D}^{\prime}$ Ans, André Marcel, Honduras: Difícil emergencia de una nación, de un Estado, Tegucigalpa, Litografía López, $2^{\mathrm{a}}$ edición, 2002, p. 171. 
escribió y publicó su famosa obra Historia social y política de Honduras en 1882, con lo que el país pudo disponer por primera vez de una historia nacional ${ }^{5}$.

De hecho, el mismo Ramón Rosa fue el autor de la presentación de la obra, y en las páginas introductorias del libro de Vallejo, anotó la trascendencia de la publicación del primer libro de historia hondureña, advirtiendo que el significado del mismo constituía una especie de radiografía o retrato moral de la nación:

Por vez primera se escribe una obra en que se relatan y aprecian los acontecimientos que, desde los tiempos cercanos á la independencia y hasta nuestros días, forman el vasto conjunto que constituye la historia social y política de Honduras... Débese en obra importante á la iniciativa del gobierno de la República, que acordó su redacción; y débese el desempeño de trabajo tan ímprobo al Señor Presbítero Licenciado Don Ramón Antonio Vallejo, quien superando dificultades sin número, ha reunido y ordenado los materiales dispersos de la Historia de Honduras, y se ha aprovechado de ellos para hacer, en la obra que hoy ve la luz pública, una exposición histórica, por orden cronológico de los sucesos prósperos ó adversos que, en lo social y político, marcan, por así decirlo, la fisonomía moral de la nación hondureña ${ }^{6}$.

El éxito de la publicación de la obra de Vallejo radicó también en la feliz decisión del gobierno de Soto de crear el "Archivo y la Biblioteca Nacional" mediante Decreto del 5 de marzo de 1880, nombrándose en la dirección al mismo Vallejo. Este hecho marcó el inicio de la investigación histórica en el país, además de la apropiación, por parte del Estado, de la responsabilidad de rescatar, organizar y conservar el legado documental que atesora la historia de la nación ${ }^{7}$.

Ramón Rosa justificó ardorosamente la creación del Archivo Nacional, pues aducía que la falta del conocimiento histórico en el país contribuía

\footnotetext{
${ }^{5}$ Cfr. Vallejo, Ramón Antonio, Compendio de la historia social y política de Honduras, Tegucigalpa, Tipografía Nacional, 1882. (BNM).

${ }^{6}$ Ibíd., p. 13.

${ }^{7}$ Sobre la fundación del "Archivo y Biblioteca Nacional deHonduras", puede consultarse por ejemplo: Rivas Fernández, José Bernal, “La creación del Archivo Nacional en la formación de la identidad nacional: los casos de Honduras y Costa Rica", En: Enríquez Solano, Francisco (Compilador), Fin de siglo XIX e identidad nacional en México y Centroamérica, Alajuela, Museo Histórico Cultural Juan Santamaría, 2000, pp. 389-399.
} 
La reforma liberal y la construcción de la figura de

Francisco Morazán como imaginario de la nación.

a la insuficiencia de identidad en la población, argumentando que "[...] un pueblo sin archivo, sin historia, sin tradiciones no puede tener un carácter que lo distinga, que lo haga representar un papel honroso en las magníficas evoluciones del progreso... no se extrañe que... este país haya estado a punto de perder hasta el último rasgo de su carácter nacional pues no ha tenido historia"8.

El historiador Steven Palmer señala que la fundación de los Archivos Nacionales centroamericanos en las postrimerías del siglo XIX, fue un recurso utilizado "por los intelectuales y politicos liberales para disponer de las fuentes necesarias para representar una antigua comunidad política nacional"9 que extendía el pasado compartido hasta la época de Cristóbal Colón y los conquistadores españoles. Este dato es sugestivo, porque la tradición historiográfica centroamericana nacida a fines del siglo XIX recreó el mito de que la "Historia" de los países de la región había arrancado en 1492 con la llegada de los españoles a América, obviando de esa manera el esplendoroso pasado histórico de los indígenas -especialmente el referido a los Mayas-, así como la participación de los negros en los anales históricos del istmo. Con ello, se empezó a fraguar una "Historia" protagonizada por élites blancas o mestizas, las que tenían la "obligación" de "civilizar" e "incorporar" a la nación homogénea a los grupos que consideraban "incultos e incivilizados", es decir, a los indígenas y negros. De ese modo, se inició una larga tradición que subordinó el pasado prehispánico al legado histórico colonial.

En todo caso, lo cierto es que la creación de los Archivos Nacionales otra de las herencias culturales de la Revolución Francesa-, tuvieron una extendida difusión en Europa y América durante el siglo XIX, y fue considerado como un instrumento de conformación nacional. La identidad compartida, sumergida en el pasado, se podía estudiar a través de los documentos, y ellos residían, como no, en los archivos; de esa forma, las versiones de la historia que comenzaron a aparecer con los archivos, contribuyeron a que los ciudadanos interiorizaran el pasado y con ello el concepto de nación ${ }^{10}$.

\footnotetext{
${ }^{8}$ Cfr. Rosa, Ramón, Oro de Honduras, Tipografía Nacional, Tegucigalpa, 1948, pp. 191.

9 Palmer, Steven, “Sociedad anónima, cultura oficial: inventando la nación en Costa Rica. 1848-1900", En: Molina Jiménez, Iván y Palmer, Steven (Editores), Héroes al gusto y libros de modas. Sociedad y cambio cultural en Costa Rica (1750-1900), San José de Costa Rica, Editorial Porvenir, 1992, p. 188.

${ }^{10}$ Rivas Fernández, José Bernal, “La creación del Archivo Nacional”... Op. cit., pp. 390-391.
} 
Con la Reforma, en el plano educativo también se lograron significativos avances, quizás los más relevantes durante todo el siglo XIX. Desde un principio, el nuevo gobierno se abocó a la tarea de promover la educación. Diversas Disposiciones y Reglamentos fueron dando estructura al nuevo sistema educativo, hasta que en 1881 tomó forma concreta a través del "Código de Instrucción Pública". En él se instituyó de manera coherente la enseñanza Primaria, Secundaria y Universitaria. En los tres niveles, la enseñanza se proclamó como laica, y para el primero, sería obligatoria y gratuita. De esta forma, la separación entre Iglesia y Estado -estipulada en la Constitución de 1880- quedó establecida y desde entonces el Estado asumió la responsabilidad de impartir conocimientos. Esto es fundamental, puesto que a partir de ese momento, se fueron formando una serie de intelectuales que fueron la generación que se encargó de continuar -a principios del siglo XX- la lenta y tortuosa conformación de la nación en Honduras.

Rápidamente, se empezaron a materializar algunos logros destacados en el campo educativo. En 1877, fueron abiertos 274 planteles que atendieron a 9,124 niños y niñas. Un año más tarde, se contabilizaban 309 escuelas en todo el país, con 10, 978 alumnos. Asimismo, se llegaron a constituir 55 escuelas para niñas que atendieron a 2,098 alumnas. Los resultados fueron hasta cierto punto alentadores, pero dada la magnitud de las necesidades escolares, el esfuerzo gubernamental todavía era insuficiente; por ejemplo, en 1881 se efectuó el primer "Censo Nacional”, el cual arrojó una cifra de 370,289 habitantes; según el padrón, cerca de la mitad de los habitantes era menor de 15 años, es decir que la población en edad escolar rondaba las 63,344 personas, y como se vio arriba, la oferta educativa apenas oscilaba en unos 10,000 alumnos, con lo cual, habían cerca de 50,000 niños que quedaban excluidos de la enseñanza. De todas maneras, lo cierto es que con la Reforma se sentaron las bases del sistema educativo moderno en Honduras ${ }^{11}$.

Por su parte, los estudios secundarios, que prácticamente apenas existían antes de la Reforma ya que en la mayoría de los casos bajo ese nombre se impartían solo nociones de filosofía escolástica y ciertos conocimientos de matemáticas, fue transformada completamente

\footnotetext{
${ }^{11}$ Yankelevich, Pablo, Honduras, México DF, Alianza Mexicana, Instituto de Investigaciones José María Luis Mora/ Universidad de Guadalajara, 1990, p. 165.
} 
La reforma liberal y la construcción de la figura de

Francisco Morazán como imaginario de la nación

cuando se fundó en Tegucigalpa "El Colegio Nacional de Enseñanza Secundaria" en 1878. Con la incorporación de asignaturas modernas como gramática española, geografía, historia, literatura, ciencias naturales, física, matemáticas e idiomas, se esperaba dar una sólida formación a los jóvenes, sobre todo de cara a su ingreso a la universidad.

Sin embargo, en el plano educativo, la pretensión más ambiciosa fue impulsar y modernizar la educación universitaria. En este sentido, el logro más sonado de la Reforma fue la reapertura de la "Universidad Central", en 1882, en la que se empezó a cultivar el sistema positivista, el cual tenía énfasis en la formación de cuadros técnicos y científicos. La rectoría de la universidad fue encomendada al Dr. Adolfo Zúniga, un cercano colaborador del régimen y uno de los liberales más reconocidos y emblemáticos de fines del siglo XIX. Una vez nombrado Zúniga en la máxima casa de estudios, la Universidad se dividió en facultades, formándose las de Jurisprudencia, Ciencias Políticas, Medicina y Cirugía y la de Ciencias. La nueva organización universitaria estableció que al término de los estudios se otorgarían los títulos de licenciado y también quedó reglamentado el sistema para la obtención de doctorados ${ }^{12}$.

Gran parte del éxito que tuvo la Reforma en el campo educativo se debió al apoyo que otorgaron varios intelectuales hondureños y extranjeros al proyecto reformista. Entre esos intelectuales, vale la pena añadir -a los ya conocidos nombres de Ramón Rosa, Ramón Antonio Vallejo y Adolfo Zúniga-, a Carlos Alberto Uclés. En cuanto a los intelectuales extranjeros, el Gobierno de Soto solicitó los servicios del famoso poeta cubano José Joaquín Palma y de manera indirecta, el también cubano José Martí apoyó la labor de la Reforma Liberal escribiendo artículos en el periódico nacional "La República".

Otros cambios que favorecieron el afianzamiento del Estado-nación durante la Reforma Liberal fueron la creación del "Correo Nacional", en el cual se nombró como director al cubano Tomás Estrada Palma, a la postre primer presidente de Cuba; este hecho fue muy trascendental, pues con ello se integró al país a la red mundial de comunicaciones; se emitieron las primeras estampillas y Honduras se adhirió además a la Unión Postal Internacional (UPI). Igualmente, se formó la "Dirección General de Estadísticas”, organizada en 1880 
para sustituir a los registros parroquiales; ésta dirección fue puesta en manos del ya citado Ramón Antonio Vallejo, quien editó el primer Anuario Estadístico de Honduras, sobre la base del primer Censo Nacional, realizado en $1881^{13}$.

La realización del Censo de 1881 fue de vital importancia en el proceso de "imaginación de la nación" llevado a cabo por los reformistas hondureños. Si bien es cierto que ya desde el periodo colonial se habían levantado censos en Honduras, el de 1881 se ejecuta con los fundamentos del positivismo. En este caso, como apunta Benedict Anderson acerca de la importancia de los censos, éstos aportan -además de la simple cuantificación de la población- una enumeración de las poblaciones que se dominan, pero también, el poder detectar las listas de aquellos a los que se les podían fijar impuestos y la conscripción militar, es decir, los Censos a fin de cuentas establecían las listas del fisco y del reclutamiento, tan importante para mantener el orden interno y la defensa de la soberanía ${ }^{14}$.

Asimismo, el Censo de 1881 -que arrojó un cómputo total de 370,289 personas-, intentaba contar minuciosamente los objetos de su imaginación nacional, y guiado por su mapa imaginario, sirvió de base para reorganizar las nuevas burocracias educativas, jurídicas, de salubridad, de policía y de inmigración, que ya para entonces era un tema central dentro de los intentos reformistas por impulsar el progreso y el desarrollo.

Adicionalmente, se reorganizó la "Tipografía Nacional", para lo cual se contrató al impresor de origen español Ramiro Fernández Robles, quien desplegó además una labor de capacitación con estudiantes interesados en el oficio seleccionados por el Estado; así, se produjo toda una generación de impresores hondureños. A la vez, empezó a tomar impulso la publicación de libros, folletos, revistas y periódicos en un grado que anteriormente no había conocido el país. Fue de hecho en este periodo cuando se fundó el primer periódico de Honduras fuera del "Diario Oficial La Gaceta", denominado diario

\footnotetext{
${ }^{13}$ Cfr. D’ Ans, André Marcel, Honduras. Difícil emergencia de una nación... Op. cit., pp. 167-168 y; Vallejo, Ramón Antonio, Primer Anuario Estadístico, Tegucigalpa, Tipografía Nacional, 1893.

${ }^{14}$ Anderson, Benedict, Comunidades imaginadas. Reflexiones sobre el origen y difusión de los nacionalismos, México DF, Fondo de Cultura Económica (FCE), 1993, p. 237.
} 
La reforma liberal y la construcción de la figura de

Francisco Morazán como imaginario de la nación

“La Paz", publicado por el grupo liberal de Soto y Rosa ${ }^{15}$.

\section{2) La "Invención de la tradición" del culto al "Panteón de los héroes nacionales" mediante la estatuaria cívica, la exaltación de la figura de Morazán y los imaginarios de nación morazánicios}

Ya con relación al proceso de creación del imaginario de Morazán como uno de los principales símbolos de la identidad nacional en Honduras, hay que señalar que uno de los espacios en los que tuvo mayor conquista la Reforma Liberal en su proceso de conformación nacional fue en el campo de la "estatuaria cívica".

En efecto, en el tránsito del siglo XIX al XX, la estatuaria cívica se convirtió en el mundo occidental en un medio idóneo para representar y evocar la memoria arquetípica de los héroes nacionales ${ }^{16}$.

Por su parte, Jacques Le Goff, en su estudio El orden de la memoria. El tiempo como imaginario, sugiere que las estatuas de los héroes que se instalaron en los Parques y plazas de las ciudades "visualizan" las glorias nacionales. La estatuaria e imaginería cívica, conceptuada como "material de la memoria", manifiesta de esa forma un carácter pedagógico y simbólico, que enlaza el pasado con el presente y lo proyecta hacia el futuro ${ }^{17}$.

Asimismo, Le Goff añade que los monumentos (en latín monumentum), son obras de carácter público que se convierten en puntos de "referencialidad" espacial y de emociones emblemáticas ante los espectadores.

En fin, el monumento o estatua es todo lo que puede hacer volver al pasado, perpetuar el recuerdo, vale decir los acontecimientos conmemorativos.

\footnotetext{
${ }^{15}$ Pérez Brignoli, Héctor y Cardoso, Ciro, Centroamérica y la economía Occidental, San José de Costa Rica, Editorial de la Universidad de Costa Rica, 1977, P. 313.

${ }^{16}$ Cfr. Brenes Tencio, Guillermo, “La estatuaria cívica: el caso de Costa Rica siglos XIX y XX”, En: Revista Ciencias Sociales, San José de Costa Rica, Vol. VII, Número 96, Junio del 2002, pp. 9-22.

${ }^{17}$ Le Goff, Jacques, El orden de la memoria. El tiempo como imaginario, Barcelona, Editorial Paidós, 1991, p. 227.
} 
Para el historiador Thomas Benjamín, los monumentos:

\begin{abstract}
Son diseñados con el fin de crear un espacio para representaciones rituales, para fiestas conmemorativas y celebraciones... El monumento, el escenario, la representación y el día particular se combinan para evocar una promesa simbólica que el Estado, el régimen o el gobernante es "fiel a los padres fundadores", y de que esa autoridad, por tanto, es legítima. Como escenarios de representaciones conmemorativas, los monumentos hacen que la gente no sólo recuerde, sino que recuerde junto a otras personas, por lo que se reafirma la solidaridad del grupo y la unidad ${ }^{18}$.
\end{abstract}

Por su parte, Donald Olsen ha revelado que los monumentos están diseñados para proyectar temor o admiración al observador, para recordarles la antigüedad de las dinastías, la riqueza de la comunidad, la verdad de la ideología que proyectan, las victorias militares o los triunfos de las revoluciones. Por eso, las estatuas representan la riqueza y sobre todo, el poder ${ }^{19}$.

En el caso de Centroamérica, Patricia Fumero ha estudiado la ritualización de la estatua del costarricense Juan Santamaría en el proceso de construcción de la nación en ese país y advierte que "[...] la estatuaria cívica se transforma en un referente espacial y del poder al brindar una serie de valores que permiten la consagración del poder que los grupos dominantes desean proyectar"20.

Con relación a Honduras y América Latina en general, durante la era liberal de finales del siglo XIX, los Estados se dieron a la tarea de acometer la instalación en sus principales espacios públicos de toda una estatuaria cívica, no solamente para el amueblamiento urbano y estético, sino con dos fines:

- Primero, mediante distintas manifestaciones escultóricas (estatuas, bustos), se construyó en el imaginario un vínculo

\footnotetext{
${ }^{18}$ Benjamín, Thomas, “La Revolución hecha monumento”, En: Revista Historia y Grafia, México DF, № 6, 1996, p. 113.

${ }^{19}$ Olsen, Donald, The City as a Work of Art. London, Paris, Vienna, Yale, University Press, 1986, p. 9.

${ }^{20}$ Fumero, Patricia, “La celebración del Santo de la Patria: La develización de la estatua al héroe nacional costarricense, Juan Santamaría, el 15 de septiembre de 1891", En: Enríquez Solano, Francisco (Compilador), Fin de siglo XIX e identidad nacional en México y Centroamérica, Alajuela, Museo Histórico Cultural Juan Santamaría, 2000, pp. 405406.
} 
La reforma liberal y la construcción de la figura de

Francisco Morazán como imaginario de la nación.

asociado a "Hombres ilustres" (Héroes, próceres y Beneméritos) con los valores y aspiraciones colectivas de la nación.

- Segundo, entre los ciudadanos y las virtudes cívicas representadas, la representación se convirtió en una máquina de fabricar respeto y sumisión.

Finalmente, como señala Brenes Tencio, el interés por mantener viva la imagen de personajes rutilantes -mediante estatuas y monumentos conmemorativos- cumplió diversos propósitos. Por un lado, contribuyó al embellecimiento del decorado urbano, y en segundo lugar, la estatuaria cívica se convirtió en un instrumento pedagógico. Ello porque las estatuas erigidas a la vista del público permitieron a las ciudadanos sentirse partícipes de una historia monumental vertida del linotipo al bronce o al granito. Siendo menos discursivos que un texto o la palabra, las estatuas (o bustos) poseen su propia relevancia: hacer que un recuerdo histórico esté indefinidamente presente, imponerlo, incluso a la gente común, pasiva e indiferente ${ }^{21}$.

En el caso de Honduras pues, es en esta época de la Reforma Liberal en que se institucionalizó el "Panteón de los héroes nacionales". Los reformadores tomaron como arquetipo de "héroe" la figura del General Francisco Morazán. De hecho, ellos eran conscientes, especialmente Ramón Rosa, de que la Reforma era una empresa que encarnaba la continuidad del proyecto federalista; así, concebían que la epopeya morazánica -interrumpida con el triunfo de los conservadores en 1839- renacía con las revoluciones liberales acaecidas a partir del último cuarto del siglo XIX; en otras palabras, "imaginaban" que el proyecto inacabado de la Federación -es decir, la consolidación de la nación-, sería consumado mediante la labor transformadora de las Reformas Liberales.

Entendemos por "Panteón de los héroes nacionales" la construcción simbólica que se erige sobre las hazañas efectuadas por personajes históricos excepcionales, algunas veces deificados y que la mentalidad colectiva ha escogido para celebrar sus acciones mediante diferentes actividades, sean ellas materiales o inmateriales ${ }^{22}$.

${ }^{21}$ Brenes Tencio, Guillermo, “La estatuaria cívica”... Op. Cit., p. 12.

${ }^{22}$ Navarrete, Federico y Olivier, Guilhem (Coordinadores), El héroe, entre el mito y la Historia, México DF, Universidad Nacional Autónoma de México (UNAM), 2000. 
Los héroes, próceres y prohombres no serán solo loados en el discurso cívico, sino también en símbolos y figuras alegóricas. De tal forma, la nación y sus héroes merecen ritos y fervor especiales en la conmemoración cívica, patriótica, republicana y nacionalista en privilegiados "lugares de la memoria".

En el caso de Honduras, desde la Reforma Liberal de 1876 el Estado desempeño un papel fundamental en el proceso de "heroización", que a la vez se insertaba dentro del proyecto de inventar la nación.

De esa forma, el régimen de Soto mandó fabricar en Europa una serie de estatuas de los héroes y próceres destacados de la etapa independentista, así como de otros personajes sobresalientes en el ámbito cultural e intelectual de los primeros años de la configuración del Estado-nación hondureño. La elaboración de las estatuas quedó aprobada según un Decreto del 27 de agosto de 1882. A tal efecto, se suscribió una contrata entre Ramón Rosa, representante del gobierno, y el ingeniero de origen italiano Francisco Durini el 29 de julio del mismo año. La estatua encomendada más importante fue desde luego la de Francisco Morazán, que fue alzada en ceremonia especial el día 30 de noviembre de 1883 en el sitio que anteriormente se denominaba como "Plaza de Armas" en el mero corazón de Tegucigalpa, la nueva capital. Con la erección del monumento al héroe unionista, el parque se conoció desde entonces como "Plaza Morazán" hasta mediados del siglo XX, tiempo desde el cual se empezó a llamar simplemente como "Parque Central" 23 .

Curiosamente, durante el siglo XX, apareció una leyenda según la cual, dicha estatua no era la de Morazán, sino -de acuerdo a algunos detractores-, la del Mariscal francés Ney; de hecho, el colombiano Gabriel García Márquez, en su discurso de aceptación del Premio Nobel en 1982, señaló -haciéndose eco de la leyenda-, que "[...] el monumento al general Francisco Morazán, erigido en la plaza mayor de Tegucigalpa, es en realidad una estatua del mariscal Ney comprada en París en un depósito de esculturas usadas" 24 . Del mismo modo, el

\footnotetext{
${ }^{23}$ Para más información sobre la contrata emitida por el gobierno de Marco Aurelio Soto para construir las estatuas de Morazán y Valle, así como los bustos de Cabañas y el Padre Reyes, puede verse: "Diario Oficial La Gaceta", Contrata celebrada por el Supremo Gobierno para que se coloquen en esta capital las estatuas de Francisco Morazán, y de José Cecilio del Valle, y los bustos de José Trinidad Cabañas, y de José Trinidad Reyes, Tegucigalpa, Suplemento al Número 174,27 de agosto de 1882. (ANH).

${ }^{24}$ Conferencia de Gabriel García Márquez, al recibir en Estocolmo el Premio Nobel de Literatura en 1982.
} 
uruguayo Eduardo Galeano, en su ya mítico libro Las venas abiertas de América Latina, tomando como fuente a García Márquez, repite la misma historia de la supuesta falsa identidad de la estatua al héroe unionista ${ }^{25}$.

Fotografía de 1882 de la estatua de Francisco Morazán recién instalada en ese entonces en la "Plaza Morazán", hoy Parque Central, (Foto original del fotógrafo cubano T. Aguirre, Archivo Jorge Amaya).

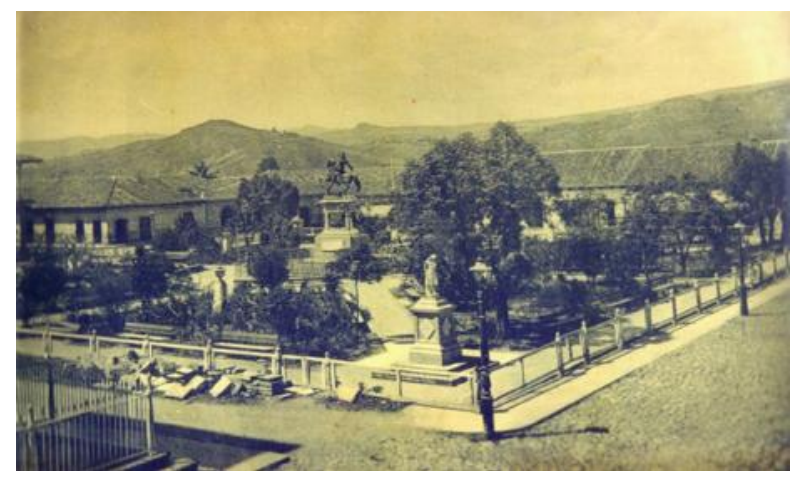

Lo cierto es que la estatua referida sí es la del general Morazán, como demostró en un documentado estudio el diplomático hondureño Rafael Leiva Vivas; él encontró en París documentación que acreditaba la autenticidad de la estatua, relatando que el contratista, Francisco Durini, a su vez, había encargado la elaboración de la estatua al escultor francés Leopold Morice, el cual fundió la pieza en los talleres de "Thiebaut Fréres". La fabricación quedó registrada en el Archivo Nacional de París -según el documento- en la sección "Estatuas Ejecutadas para el Extranjero", con la signatura F12-528326.

Desde entonces, Morazán se convirtió en el prócer hondureño más "ritualizado" en los espacios públicos de las principales ciudades del país, pues existen estatuas o bustos suyos en otras ciudades como San Pedro Sula, La Ceiba, Amapala, Choluteca, Santa Bárbara, Santa Rosa de Copán y Trujillo entre otras; se podría decir a la vez que es el centroamericano que ostenta mayor cantidad de efigies alrededor del mundo, ya que existen iconografías de él en todas las capitales de Centroamérica, así como en otras ciudades del resto del mundo como Nueva Orleáns, Lima, Caracas, Santiago de Chile, México DF y Madrid $^{27}$.

\footnotetext{
${ }^{25}$ Galeano, Eduardo, Las venas abiertas de América Latina, Madrid, Siglo XXI Editores, 3ª edición, 1982, p. 432.

${ }^{26}$ Véase: Leiva Vivas, Rafael, Francisco Morazán y sus relaciones con Francia, Tegucigalpa, Editorial Universitaria, Colección Homenajes, № 3 1ª̣ edición, 1988, pp. 136.

${ }^{27}$ Acerca de la representación de Morazán en estatuas y otros medios consúltese: Jerez Alvarado, Rafael, Monumentos y elogios al General Morazán, Tegucigalpa, 1986, S/N, p. 141.
} 
Otro elemento que contribuyó a forjar el imaginario de Morazán como principal fuente de identidad en Honduras fue la reconstrucción de su vida como vehículo de imitación ciudadana a través de la redacción y difusión de sus Historia y su biografía. De hecho, el mismo Ramón Rosa escribió una obra -probablemente la primera biografía escrita en el país- sobre la vida del héroe, titulada Historia del Benemérito General Don Francisco Morazán ${ }^{28}$.

Desde entonces, historiadores, poetas, narradores, teatristas, pintores y casi todos los intelectuales del país han escrito o publicado obras alusivas a la historia del General Morazán. En este sentido, posiblemente Morazán sea el personaje de la Historia hondureña más estudiado en el país ${ }^{29}$.

Igualmente, desde la Reforma Liberal Morazán quedó firmemente vinculado con la principal "Fiesta cívica" en el calendario de efemérides hondureña: "La Celebración de la Independencia del 15 de Septiembre", pues entre finales del siglo XIX y hasta la década de los años 60 del siglo XX, los desfiles del "15 de Septiembre" solían culminar en la rotonda de la estatua del General en el Parque Central.

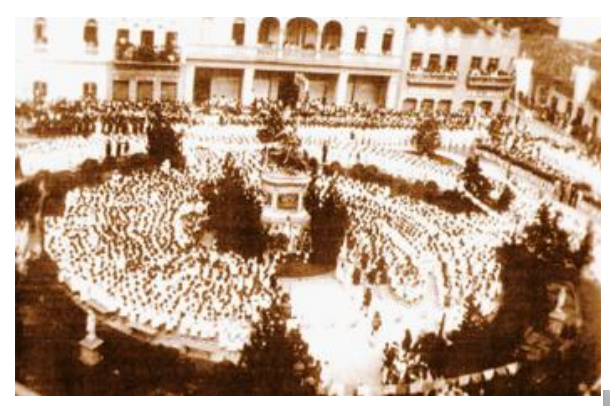

Desde este momento de la Reforma Liberal se empezaron a institucionalizar las "Fiestas cívicas", como el Día de la Independencia, que culminaba con el desfile alrededor de la estatua de Morazán. (Foto archivo de Jorge Amaya).

Coronación de la estatua del General Morazán por parte del dictador Tiburcio Carías, en ocasión de la celebración del centenario de la muerte del prócer en 1942. (Foto archivo de Jorge Amaya).

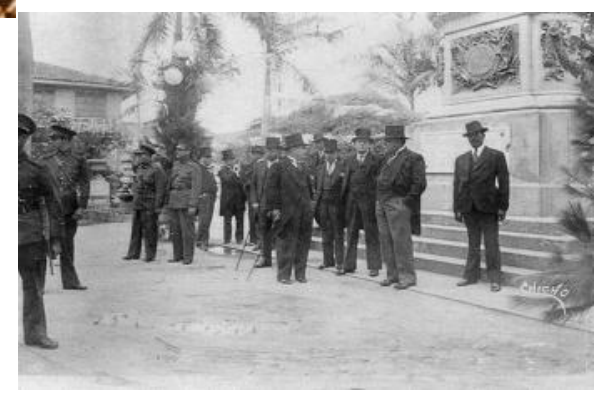

${ }^{28}$ Rosa, Ramón, Historia del Benemérito General Don Francisco Morazán, Tegucigalpa, 1971.

${ }^{29}$ Sobre este punto vale revisar: Umaña, Helen, Morazán en la literatura hondureña, San Pedro Sula, Centro Editorial, 1995.

<PARADIgMA> - Revista de Investigación Educativa. Año 20. No. 31 
Finalmente, Morazán ha sido un poderoso instrumento de identificación nacional, de modo que su nombre se ha internalizado en la conciencia colectiva con el fin de nombrar espacios, lugares, instituciones, negocios, barrios, escuelas y hasta instancias de la vida cotidiana como estadios, cafeterías, hoteles y cantinas; así, existen en toda Honduras espacios con sus nombres: “Estadio Morazán" en San Pedro Sula, "Represa Francisco Morazán” en El Cajón, "Bulevar Morazán” en Tegucigalpa, “Barrio Morazán” en Tegucigalpa, "Universidad Pedagógica Nacional Francisco Morazán UPNFM" en la misma capital, una academia de policía, la "Academia Francisco Morazán"; en monedas, de hecho, en San José de Costa Rica hay también una "Cantina Morazán". Para agregar a esta parafernalia, la máxima presea que otorga el Estado de Honduras se denomina “Orden de Francisco Morazán". Se podría decir que en el caso de la cultura e identidad hondureña ha habido por tanto un fuerte proceso de "morazanización" de su identidad.

De alguna manera, la consecuencia de este proceso de "heroización" y "deificación" de la figura de Morazán contribuyó a forjar una historiografía de corte liberal. La historiografía de la triunfante Reforma Liberal ubicó el origen de la "Historia Patria" en la Independencia contra España de 1821, y Morazán se convirtió en una especie de "Pater Patriae" y en el inmaculado gestor de los ideales liberales y reformadores. En contraposición, esta historiografía liberal satanizó a los personajes históricos opositores o enemigos de Morazán ligados al conservadurismo, como por ejemplo Francisco Ferrera, José Santos Guardiola o José María Medina, quienes fueron difamados y desprestigiados en los libros de texto de historia, o en el mayor de los casos condenados a un limbo histórico.

Esta visión historiográfica liberal que exaltó a Morazán y ensombreció a los conservadores condujo a la difusión de discursos nacionalistas liberales, y por ende a la constitución de una "Historia maniquea" entre buenos (los liberales) y malos (los conservadores).

Desde 1876, esta visión histórica fue también la que se empezó a desplegar en las escuelas, colegios y universidades del país, convirtiéndose entonces en la que es denominada por algunos historiadores como "Historia didáctica", nombrada también por el historiador mexicano Luís González como "Historia de bronce" o 
"Historia reverencial" ${ }^{30}$.

Esta forma de hacer historia aún divide a los actores sociales que forman parte en los hechos históricos entre buenos y malos. Con inusitada frecuencia en un extremo aparecerán los héroes - sin mencionar sus errores - y en el otro se ubicarán los traidores, los vende-patrias, sin que se les reconozca cualidad alguna. Esta historia es la preferida por las instituciones gubernamentales, pues configura a los "grandes hombres" como personajes con quienes es fácil identificarse debido a su presentación como seres casi único, extraordinarios.

En suma, creemos que la figura de Morazán ha sido un instrumento discursivo de identidad nacional por antonomasia en Honduras. Es posible que con los brutales acontecimientos generados a partir del Golpe de Estado de junio del 2009 y la toma de conciencia nacionalista entre la intelligentsia progresista y de izquierda, la visión de Morazán tienda a ser revisitada desde un enfoque que rescate a un Morazán más revolucionario y elevado a una estatura continental en la línea de Simón Bolívar.

Sin duda, a pesar de esa perspectiva maniquea, es difícil negar que Morazán sea quizás el personaje de la Historia hondureña con mayor dimensión continental e incluso universal.

Finalmente, es importante exponer que la figura de Morazán ha sido tan poderosa en la construcción de imaginarios de identidad nacional, que incluso ha sido tomado como bandera de lucha por ideologías e instituciones tan disímiles como los militares de extrema derecha fascista, por el Partido Liberal, por grupos guerrilleros de izquierda en los años 80 como el legendario Frente Morazanista de Liberación Nacional (FMLN), y hoy en día por el Frente Nacional de Resistencia Popular (FNRP).

Por otro lado, también, el gobierno de la Reforma Liberal ordenó esculpir una estatua de José Cecilio del Valle, mediante el mismo Decreto del 27 de agosto de 1882, la cual fue situada solemnemente en la "Plaza de San Francisco", en el parque que hoy lleva su nombre en el centro de Tegucigalpa. Al igual que Morazán, Valle quedó

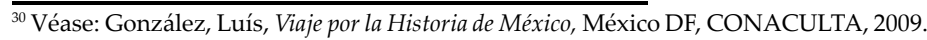


La reforma liberal y la construcción de la figura de

Francisco Morazán como imaginario de la nación.

inmortalizado en el calendario cívico hondureño establecido durante la Reforma Liberal. Hoy en día, el Palacio Presidencial, una Universidad y un sinfín de escuelas y colegios a lo largo y ancho del país, llevan el nombre del sabio Valle y además, el día 22 de noviembre, fecha de su natalicio, es día de fiesta nacional en la que se entregan los Premios Nacionales de Ciencia "José Cecilio del Valle".

Por otra parte, también se comisionó la confección de otras estatuas, como la de Dionisio de Herrera ${ }^{31}$, el primer Jefe de Estado de Honduras (1824-1827), mentor de Morazán y baluarte de la primera generación liberal hondureña; el busto fue instalado en el Parque que hoy lleva su nombre, frente al Teatro Nacional de Tegucigalpa. Asimismo, se esculpieron los bustos en mármol de Carrara del presidente José Trinidad Cabañas y del presbítero José Trinidad Reyes, fundador de la Universidad hondureña. Ambos bustos fueron colocados en la "Plaza de la Merced". Al pie de la efigie de Cabañas se lee una inscripción que reza: "Al heroico soldado de la unión de Centro América. Al guerrero modelo de valor, constancia, de honradez, y de lealtad"; por su parte, en el pedestal del padre Reyes resaltan dos leyendas que dicen: "Al más ilustre iniciador de la Ilustración pública", "Al profundo filósofo de la naturaleza. Al sacerdote que ejerció un alto ministerio de paz, mansedumbre y caridad". Todavía después, en el año de 1923, el 28 de mayo, con el propósito de exaltar a los hondureños y hondureñas que dedicaban su vida al estudio, el Estado acordó celebrar el 11 de junio -natalicio del Padre Reyes-, como “Día de Fiesta Nacional para los escolares", con lo que quedó institucionalizado el 11 de junio como "Día del Estudiante".

\footnotetext{
${ }^{31}$ José Dionisio de la Trinidad Herrera Díaz del Valle nació en Jerez de la Choluteca, Provincia de Honduras, el 9 de octubre de 1781. Sus padres fueron don Juan Jacinto Herrera y doña Paula Díaz del Valle Izaguirre, rama por la cual era primo con José Cecilio del Valle. Fue bautizado por fray José Ginés de Mayorga el 25 de octubre de 1781. De pequeño, se trasladó con su familia a Tegucigalpa y luego se graduó de abogado en la Universidad San Carlos de Borromeo de Guatemala. Contrajo matrimonio en 1820 con doña Micaela Quesada Borjas, hermana de la madre del general Morazán, por lo tanto, se convirtió en tío político de éste.

Siendo simpatizante de la Revolución Francesa y partidario de la independencia centroamericana, actuó como protagonista de dicho evento. El último alcalde español de Tegucigalpa, don Narciso Mallol, lo nombró Secretario del Ayuntamiento el 7 de agosto de 1820 . Una vez proclamada la independencia el 15 de septiembre de 1821 , se adhirió a la misma, cuando el 28 del mismo mes -fecha en que llegaron a Tegucigalpa los pliegos de la independencia-, redactó un acta complementaria aceptando y ratificando la liberación. Instaurada la República Federal de Centroamérica en 1824, se convirtió en el primer Jefe de Estado de Honduras entre septiembre de ese año y mayo de 1827.
} 


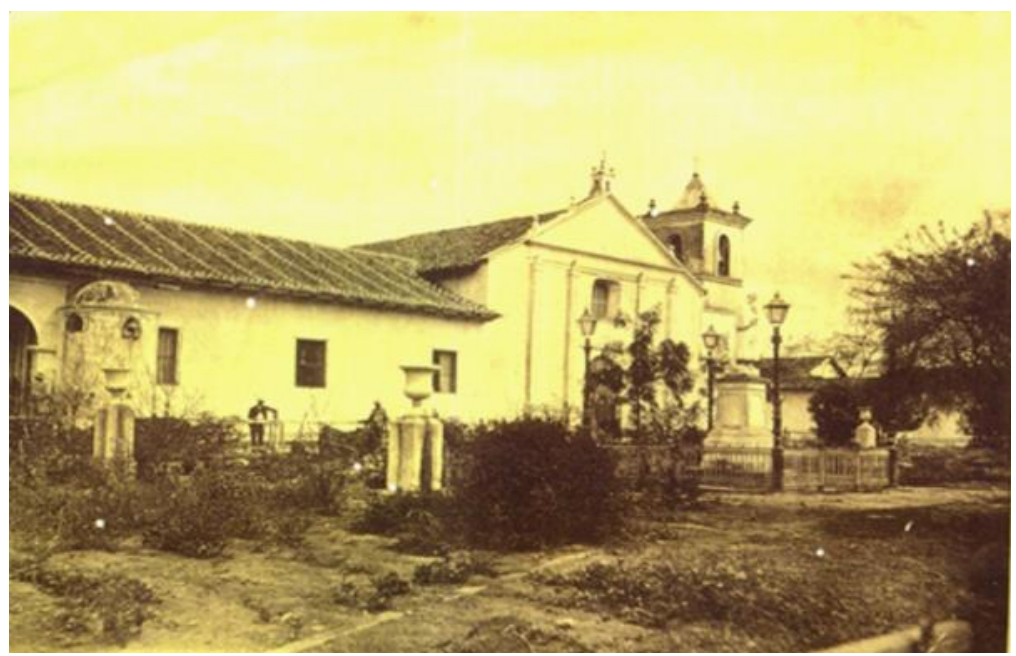

Estatua de José Cecilio del Valle en el "parque Valle" de Tegucigalpa.

Por medio de la estatuaria, los reformadores convirtieron a Morazán, Valle, Herrera y otros próceres y personajes en los máximos héroe de la nación, y a partir de ese momento se constituyeron en un "imaginario" que pasó a ocupar los principales espacios públicos de las ciudades y pueblos hondureños, ya que además de las estatuas, existen boulevares, calles, escuelas, universidades centros culturales y otros sitios que llevan sus nombres. 
La reforma liberal y la construcción de la figura de Francisco Morazán como imaginario de la nación
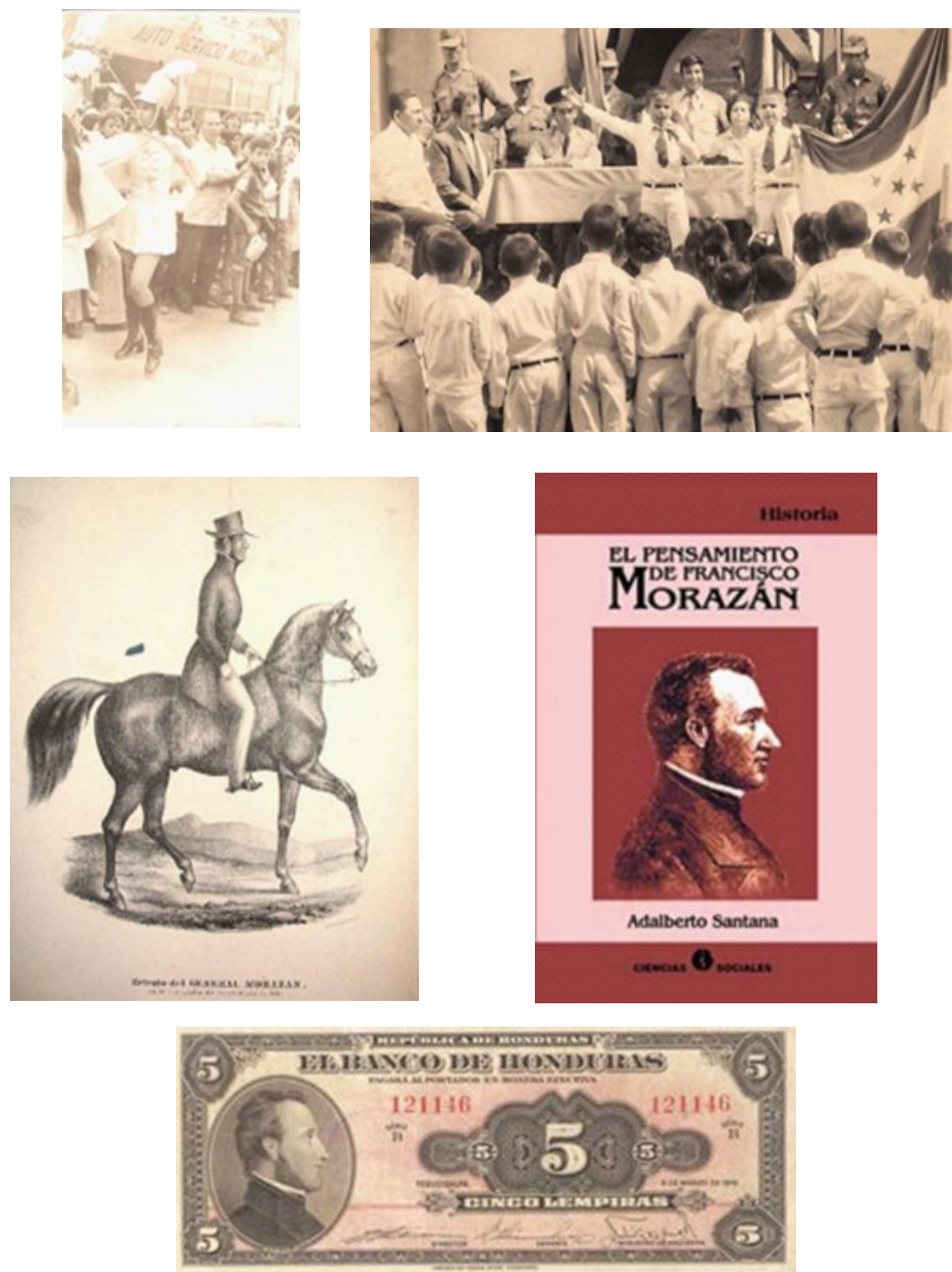

De arriba hacia abajo, diferentes instancias de representación de Morazán ligado con los imaginarios de nación en Honduras. Primero, una joven "Palillona" o "Pomponera" hondureña en un desfile de las "Fiesta Cívica" de la Independencia del 15 de Septiembre en los años 60; luego, un escolar hondureño declamando en una Escuela de Gracias Lempira en los años 70 en un acto cívico en homenaje a Morazán; después un grabado de Morazán de los que se acostumbra estampar en las aulas de las escuelas hondureñas; luego la portada de un libro de texto que recoge la biografía de Morazán, y por último, un billete de 5 lempiras con la efigie de Morazán. (Fotos archivo de Jorge Amaya). 

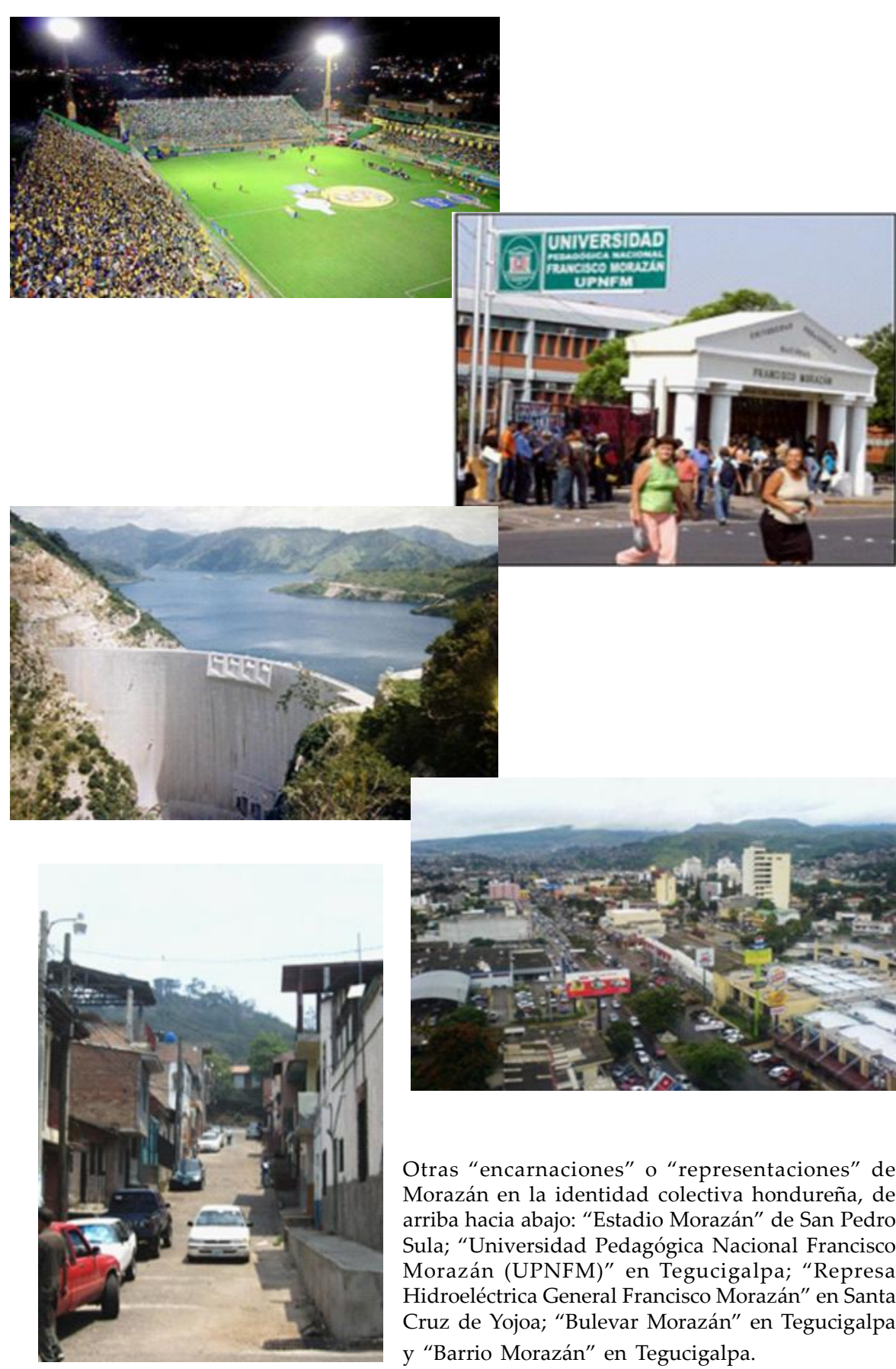

Otras "encarnaciones" o "representaciones" de Morazán en la identidad colectiva hondureña, de arriba hacia abajo: “Estadio Morazán" de San Pedro Sula; "Universidad Pedagógica Nacional Francisco Morazán (UPNFM)" en Tegucigalpa; "Represa Hidroeléctrica General Francisco Morazán" en Santa Cruz de Yojoa; "Bulevar Morazán” en Tegucigalpa y “Barrio Morazán” en Tegucigalpa. 

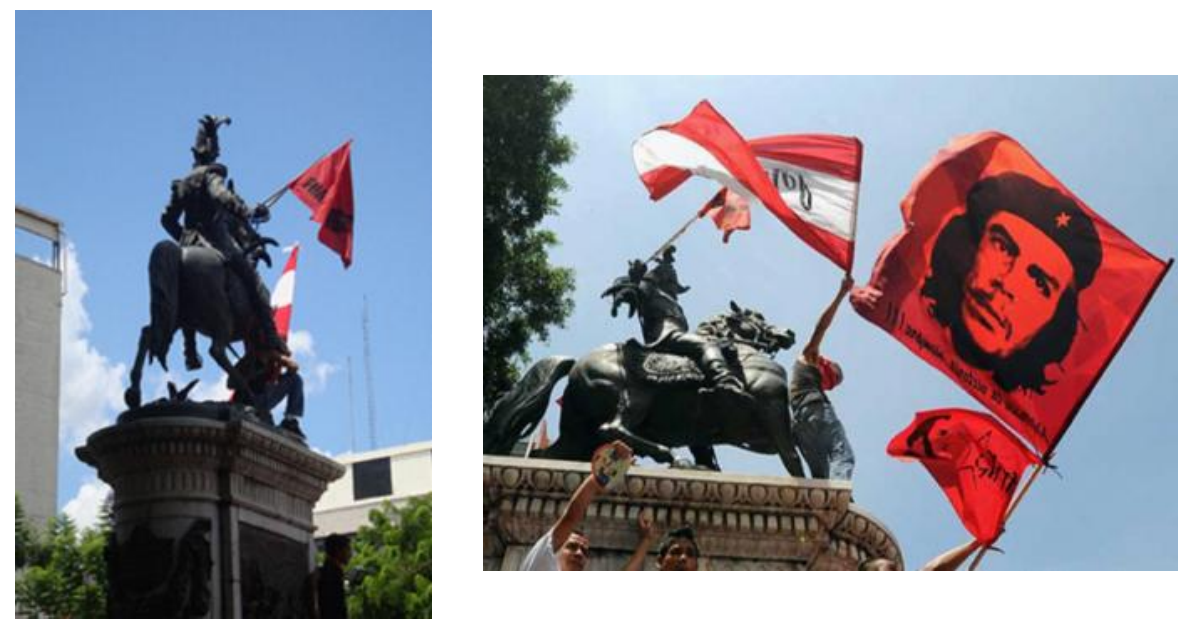

Dos manifestaciones políticas del Frente Nacional de Resistencia Popular en el Parque Central de Tegucigalpa, en las que se manifiesta que los seguidores de la Resistencia se apoderan "simbólicamente" de la plaza y de la Estatua, convirtiéndolos en "espacio de memoria" orientada a la rebelión.

Toda esta parafernalia sustentada en la proliferación de la estatuaria respondía al esfuerzo centralizador que el régimen de Soto buscaba proporcionar al Estado-nación hondureño. En todo caso, lo cierto es que la Reforma aportó las bases del panteón de los héroes nacionales, encabezado por Francisco Morazán, Dionisio de Herrera, José Trinidad Cabañas y José Cecilio del Valle. Todos esos símbolos han trascendido hasta nuestros días, transmitidos de generación en generación a través del sistema educativo y más recientemente mediante los medios masivos de comunicación. También, el carácter épico o legendario quedó signado por la "ritualización" específica que se hizo de cada una de esas "imágenes"; así, por ejemplo, Morazán, Herrera y Cabañas quedaron proclamados como los "héroes" unionistas, defensores de la República Federal; Valle como el intelectual ilustrado, el "sabio" más glorioso que ha parido Honduras y al Padre Reyes se le honró como el "protector" de la cultura nacional y de la educación ${ }^{32}$.

En resumen, La Reforma Liberal hondureña constituyó un acontecimiento de trascendental importancia en la historia del país y sentó las bases para una modificación sustancial de las viejas estructuras heredadas del período colonial; asimismo, ejerció una

\footnotetext{
${ }^{32}$ Sobre este asunto puede consultarse entre otros: Barahona, Marvin, Evolución histórica de la identidad nacional Tegucigalpa, Editorial Guaymuras, Colección Códices de Ciencias Sociales, 1990, pp. 243 y 244.
} 
influencia profunda en el ulterior desarrollo de la historia nacional. Con ella, se cimentaron los fundamentos que dieron forma más estable y centralizada al Estado-nación hondureño, inventando gran parte de los símbolos y elementos identitarios que configuran los imaginarios de nación en Honduras, tarea que fue continuada afanosamente por las generaciones políticas e intelectuales subsiguientes, sobre todo las de la primera mitad del siglo XX, tiempo durante el cual todavía se proseguía la labor de reproducir otras "imágenes" en las cuales se fuera identificando al pueblo con la nación. 